\title{
Treatment of condyloma acuminata with 5 per cent. 5-fluorouracil (5-FU) cream
}

TO THE EDITOR British fournal of Venereal Diseases

SIR-Condyloma acuminata are very common in both sexes. Electron microscopical studies have suggested that a papillomavirus in low concentration is present in these warts (Oriel and Almeida, 1970). This virus is antigenically different from that of the common skin wart (Almeida, Oriel, and Stannard, 1969). Condyloma acuminata can disappear spontaneously but this process is generally so slow that most patients require treatment. Temporary clearance can be achieved by a variety of treatments-podophyllin resin, a cytotoxic agent, is commonly used in various vehicles and concentrations. Although the efficacy of this agent has been established (cure rates have ranged from 25 to 70 per cent.), local reactions, which can be severe, are frequently encountered.

5-Fluorouracil (5-FU) is a cytotoxic agent which can also act as a potent topical chemotherapeutic agent in various skin neoplasms (De Moragas and GimenezCamarasa, 1970). It has been claimed that topical application does not produce adverse local reactions or systemic effects (Ott, Eichenberger-De Beer, and Storck, 1970).

The efficacy of 5-FU in condyloma acuminata was investigated in 100 patients of both sexes who were attending the Department of Venereal Diseases at the Birmingham General Hospital and had received no previous treatment. A 5 per cent. cream of 5-FU was prepared by the hospital pharmacy for this work since this concentration of 5-FU had been shown to give the best results in skin neoplasms (Stoll, Klein, and Case, 1967). This cream was gently massaged into each wart with an orange stick or a fine cotton-wool swab. Treated sites were not occluded and patients were instructed to wash the treated areas if any local inflammatory reactions occurred. The 100 patients were examined and treated on a weekly basis for 4 weeks, at the end of which only 10 per cent. of them had been completely cured. No adverse local reactions were recorded.

After this study of 100 patients, a further ten untreated patients with condyloma acuminata were given 5 per cent. 5-FU cream to be applied (with either an orange stick or a cotton-wool swab) to their warts once daily. They were all warned about adverse reactions and were examined in the clinic weekly. As a result of this course of therapy five out of ten were cured within 4 weeks. Those who had not been cured by this time were treated with podophyllin. Lesions of the anal region seemed particularly susceptible to 5 -FU. This is interesting since it has been pointed out by Klostermann (1970) that there were some "regional" differences in the penetration and absorption of 5-FU.

Theoretically 5-FU should prove useful in condyloma acuminata. The 100 cases studied showed that weekly applications, although free from side-effects, produced only a 10 per cent. cure rate in 4 weeks. In the few cases treated with daily applications the results were much more encouraging. Nel and Fourie (1973) treated eleven patients with condylomata acuminata with 5 per cent. 5-FU ointment applied once daily by the patient for an average period of 8 weeks. They claimed complete regression of the warts in eight patients, partial regression in two, and no improvement in one. It is therefore suggested that further trials with varying times of application and concentrations of 5-FU would be worthwhile.

$$
\text { Yours faithfully, }
$$

K. R. HAYE

SPECIAL TREATMENT CENTRE

MANCHESTER ROYAL INFIRMARY, OXFORD ROAD,

MANCHESTER M13 9WL.

August 28, 1974

I should like to thank Dr W. Fowler for allowing me to treat his patients at the Birmingham General Hospital.

\section{References}

Almeida, J. D., Oriel, J. D., and Stannard, L. M. (1969) Microbios, 3,225

De Moragas, J. M., and Gimenez-Camarasa, J. M. (1970) Dermatologica (Basel), 140, Suppl. 1, p.65

KLOSTERMANN, G. F. (1970) Idem, p.47

NeL, W. S., and Fourie, E. D. (1973) S. Afr. med. f., 47, 45

ORIEL, J. D., and AlMEIDA, J. D. (1970) Brit. F. vener. Dis., 46, 37

OTt, F., EichenBERGER-De BeER, H., and StORCK, H. (1970) Dermatologica (Basel), 140, Suppl. 1, p.109

Stoll, H. L., Jr., Klein, E., and CaSe, R. (1967) f. invest. Derm., 49, 219 